\title{
Effect of sorafenib on cisplatin-based chemoradiation in head and neck cancer cells
}

\author{
Nikolaus Möckelmann ${ }^{1}$, Thorsten Rieckmann ${ }^{1,2}$, Chia-Jung Busch ${ }^{1}$, Benjamin \\ Becker $^{1,2}$, Lisa Gleißner ${ }^{2}$, Konstantin Hoffer ${ }^{2}$, Maria Omniczynski², Leonhard \\ Steinmeister ${ }^{2}$, Simon Laban ${ }^{1,5}$, Reidar Grénman ${ }^{3}$, Cordula Petersen ${ }^{4}$, Kai \\ Rothkamm², Ekkehard Dikomey ${ }^{2,4}$, Rainald Knecht ${ }^{1}$ and Malte Kriegs ${ }^{2}$ \\ ${ }^{1}$ Head and Neck Cancer Center of The University Cancer Center Hamburg (UCCH), Department of Otorhinolaryngology and \\ Head and Neck Surgery, University Medical Center Hamburg-Eppendorf, Hamburg, Germany \\ ${ }^{2}$ Head and Neck Cancer Center of The University Cancer Center Hamburg (UCCH), Laboratory of Radiobiology \& Experimental \\ Radiooncology, University Medical Center Hamburg-Eppendorf, Hamburg, Germany \\ ${ }^{3}$ Department of Otorhinolaryngology - Head and Neck Surgery and Department of Medical Biochemistry and Genetics, Turku \\ University and University Hospital of Turku, Turku, Finland \\ ${ }^{4}$ Head and Neck Cancer Center of The University Cancer Center Hamburg (UCCH), Department of Radiotherapy and \\ Radiooncology, University Medical Center Hamburg-Eppendorf, Hamburg, Germany \\ ${ }^{5}$ Department of Otorhinolaryngology and Head and Neck Surgery, Ulm University Medical Center, Ulm, Germany \\ Correspondence to: Nikolaus Möckelmann, email: n.moeckelmann@uke.de
}

Keywords: HNSCC, sorafenib, molecular targeting, radiosensitization, cisplatin

Received: January 23, $2016 \quad$ Accepted: March 01, 2016

Published: March 22, 2016

\section{ABSTRACT}

Despite aggressive chemoradiation (CRT) protocols in the treatment of patients with head and neck squamous cell carcinomas (HNSCC), the outcome is still unfavorable. To improve therapy efficacy we had already successfully tested the multikinase inhibitor sorafenib in combination with irradiation (IR) in previous studies on HNSCC cell lines. In this study we investigated its effect on combined CRT treatment using cisplatin.Radio- and chemosensitivity with and without sorafenib was measured in four HNSCC cell lines and normal fibroblasts (NF) by colony formation assay. Apoptosis and cell cycle analysis were performed by flow cytometry.

In HNSCC cells, sorafenib enhanced the antiproliferative effect of cisplatin without affecting apoptosis induction and with only minor effects on cell inactivation. Sorafenib added prior to irradiation enhanced cellular radiosensitivity in three of the tested HNSCC cell lines and caused massive overall cell inactivation when combined with CRT. In contrast, sorafenib did not radiosensitize NF and reduced cisplatininduced cell inactivation. Cell inactivation by IR and cisplatin is further increased by the addition of sorafenib in HNSCC, but not in NF cells. Therefore, sorafenib is a promising candidate to improve therapy efficacy for HNSCC.

\section{INTRODUCTION}

Most head and neck squamous cell carcinomas (HNSCC) are diagnosed in a locoregionally advanced stage (stage III to IVB), for which a single treatment modality is ineffective. Therefore, these patients are treated with combined therapeutic regimens including surgery, radiation, and chemotherapy. The standard therapy is a platinum-based chemotherapy either given sequentially or concomitant to radiotherapy (RT). Despite this aggressive treatment, tumour recurrence rates are high and the five-year survival rate for these patients is still limited to $30-40 \%$, but adverse side effects lead to reduced compliance rates of CRT treated patients and prohibit further dose escalation [1-6]. In order to improve the efficacy of chemoradiation (CRT) for HNSCC patients, without increasing the side effects on normal tissue, targeted therapeutics have been added to the standard regimens using either monoclonal antibodies $(\mathrm{mAb})$ or small molecule inhibitors in clinical trials.

Besides some alternative strategies, so far the focus of molecular targeting for HNSCC patients has been on the 
inhibition of the epidermal growth factor receptor (EGFR). However, recent pre-clinical and clinical data suggest that EGFR inhibition might not improve tumor control and response especially to CRT $[7,8]$. Therefore new effective strategies have to be evaluated in order to improve the efficacy of CRT treatment without increasing normal tissue damage. Although, the majority of the tested targeted therapeutics could not show an improvement in antitumor activity of the combined treatment with CRT until now [7], some agents are still under clinical investigation as part of trials (NCT01737008, NCT01824823, NCT02131155, NCT00442455, NCT00629226).

In this context the multi-target kinase inhibitor sorafenib seems to be promising. Sorafenib is already FDA approved for the treatment of different tumor entities [9-11]. In HNSCC, sorafenib has only been investigated clinically in the palliative setting without radiotherapy $[12,13]$. However, we have already demonstrated, that sorafenib inhibits proliferation, causes approximately $50 \%$ of cell inactivation and is able to radiosensitize human papilloma virus (HPV)-negative HNSCC cells effectively [14], which is in line with data from other groups and for other tumor entities [15-18]. Furthermore, we were able to show that radiosensitization is likely mediated by inhibition of DNA double strand break repair [14]. However, the effect of sorafenib on irradiation in combination with cisplatin chemotherapy has not been evaluated so far, either for HNSCC or for normal cells with the latter potentially indicating normal tissue damage.

Since cisplatin-based CRT is the standard treatment for advanced HNSCC, the aim of this study was to investigate the effects of sorafenib on HNSCC and normal cells treated with both irradiation and cisplatin in order to evaluate this combination for further pre-clinical investigations using xenograft tumors.

\section{RESULTS}

\section{Effect of sorafenib on radiosensitivity}

In a previous study we reported a radiosensitizing effect of sorafenib on HNSCC cell lines [14]. We verified this finding by screening a panel of 20 different HNSCC cell lines by colony formation assay under delayed plating conditions resulting in five cell lines which could be sensitized to ionizing radiation by sorafenib (data not shown). For further studies, we chose four cell lines, one which does not become sensitized $(\mathrm{FaDu})$ and three which become sensitized, either to a small (UT-SCC 42A), a moderate (SAS) or a large (UT-SCC 60B) extent (Figure $1)$. In all cell lines tested, sorafenib additionally caused a

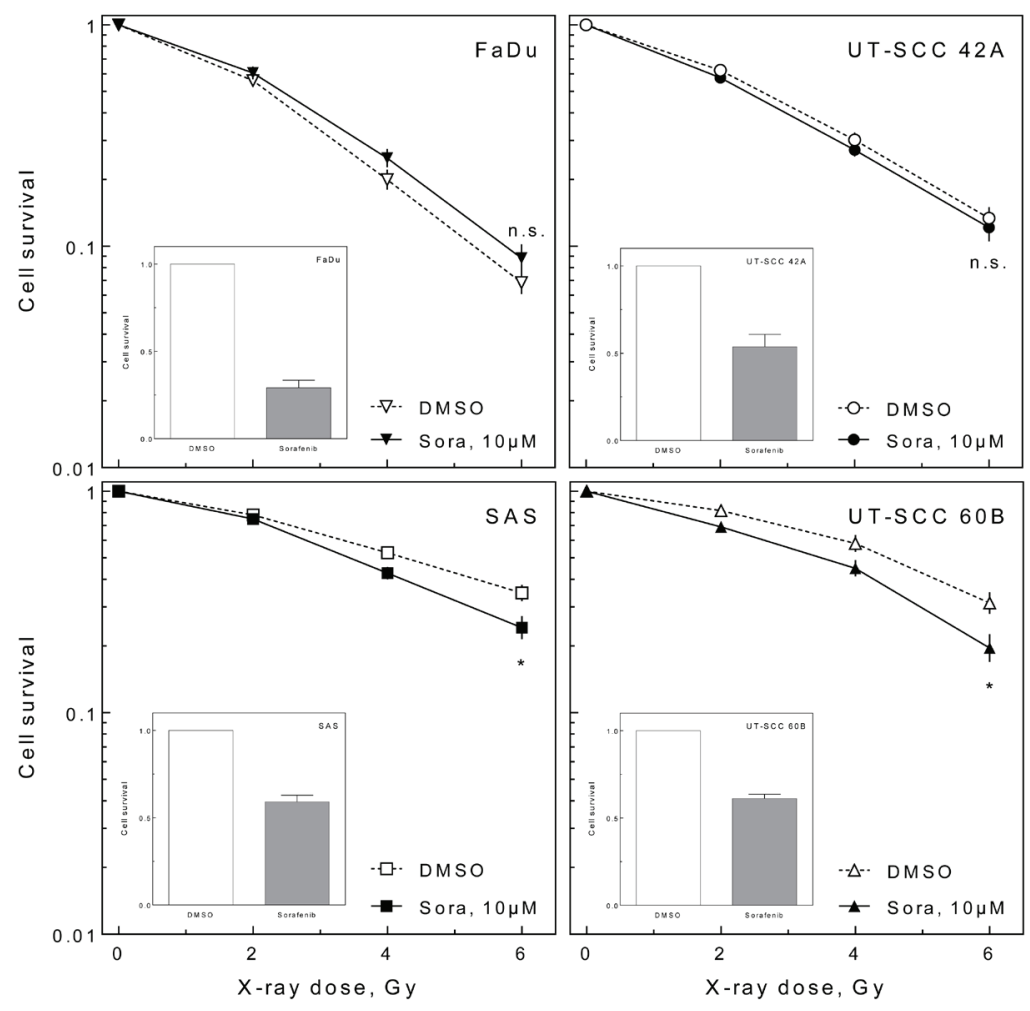

Figure 1: Effect of sorafenib on cellular radiosensitivity. Exponentially growing HNSCC cells were irradiated with doses up to 6 Gy with or without $10 \mu \mathrm{M}$ sorafenib pre-treatment for $2 \mathrm{~h}$. Twenty-four hours later cells were re-plated (delayed plating). The relative radiosensitivity (large graph) and the relative cytotoxic effect of sorafenib alone (small inlayed graphs) were determined using the colony forming assay. 
cytotoxic effect of approximately $50 \%$ (Figure 1 inlays). For FaDu and UT-SCC 42A these responses had been reported previously [14].

\section{Effect of sorafenib on cisplatin treatment}

To test the effect of sorafenib on cisplatin, we analyzed UT-SCC 42A cells in terms of proliferation, apoptosis and cell cycle. Because sorafenib had a dosedependent antiproliferative effect with maximal growth inhibition at $10 \mu \mathrm{M}$ (Figure $2 \mathrm{~A}$ ), we used $5 \mu \mathrm{M}$ sorafenib to analyze cell proliferation in combination with cisplatin. As shown in Figure 2B, cisplatin alone induced a dosedependent growth inhibition, which was further enhanced by sorafenib. This effect could not be attributed to an increase in cisplatin-induced apoptosis (Figure 2C) or a pronounced cell cycle arrest (Figure 2D), since even 10 $\mu \mathrm{M}$ sorafenib caused only a small additional S-phase delay and G2-phase arrest compared to the samples treated with cisplatin only .

To test whether enhanced inhibition of proliferation by sorafenib also causes improved cell inactivation in combination with cisplatin, we performed colony formation assays. Therefore cells were treated for 24 $\mathrm{h}$ with $10 \mu \mathrm{M}$ sorafenib and different concentrations of cisplatin (1-10 $\mu \mathrm{M}$; pre-plating). The effect of cisplatin alone varied, with $\mathrm{FaDu}$ cells being very sensitive towards cisplatin while UT-SCC 42A cells were quite resistant (Figure 3). Adding sorafenib caused heterogeneous effects, with UT-SCC 42A and SAS cells becoming slightly more sensitive while UT-SCC 60B cells became significantly more resistant. Like under delayed plating conditions sorafenib caused an additional cytotoxic effect (Figure 3 inlays).

\section{A}

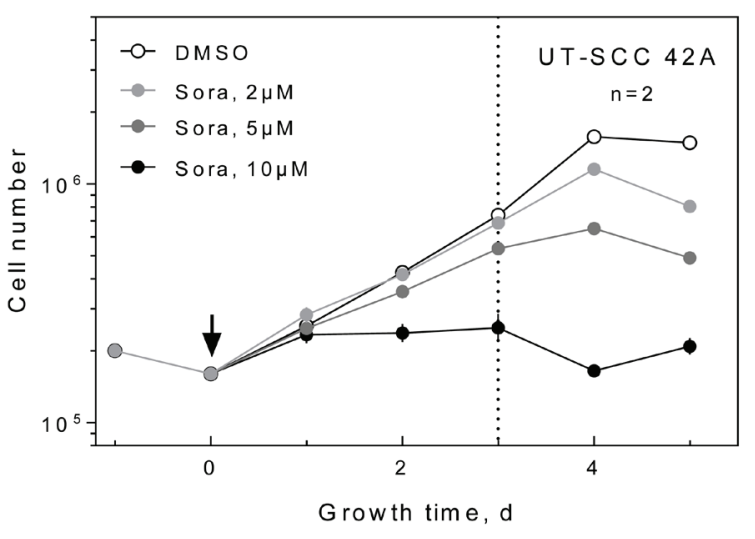

B
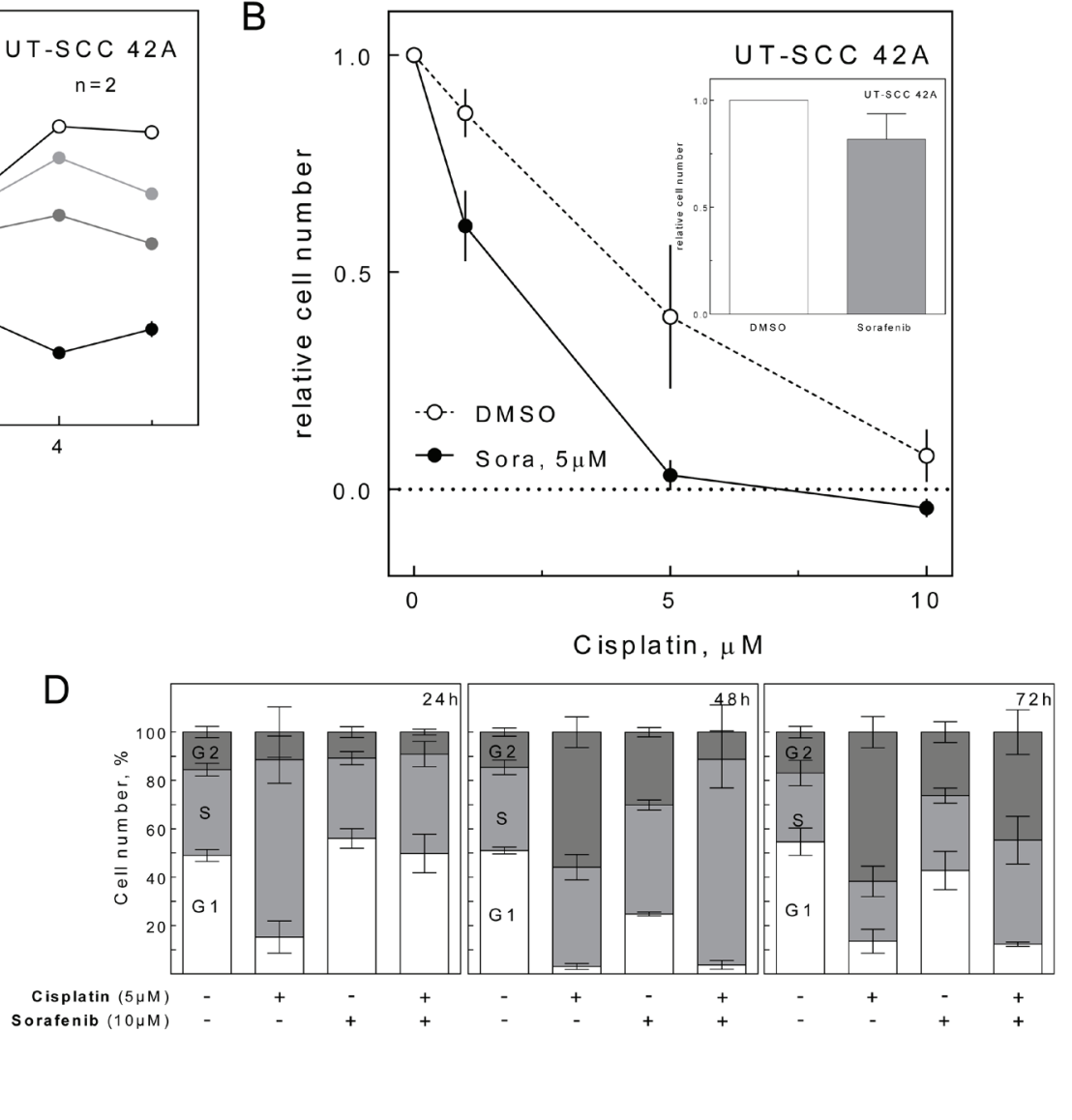

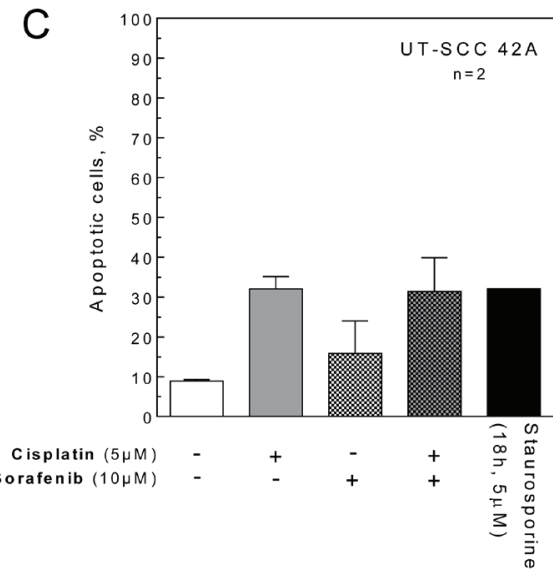

Figure 2: Effect of sorafenib on proliferation, apoptosis and cell cycle. A. Inhibition of cell proliferation. UT-SCC 42A cells were treated with sorafenib as indicated and the cells were counted daily up to $5 \mathrm{~d}$ after sorafenib addition. The absolute cell numbers are depicted. B. Enhancement of the anti-proliferative effect of cisplatin. Cells were treated with increasing concentrations of cisplatin with and without $5 \mu \mathrm{M}$ sorafenib. Three days later, the cell number was quantified, the number of plated cells was subtracted and the numbers were normalized to the untreated control. The fraction of treated cells compared to control (DMSO-treated) cells is depicted. The relative effect of sorafenib alone is given in the inlay. C. Induction of apoptosis. Cells were treated with $10 \mu \mathrm{M}$ sorafenib and $5 \mu \mathrm{M}$ cisplatin. Shown is the percentage of apoptotic cells after $72 \mathrm{~h}$ treatment as measured by flow cytometry. Cells were incubated with $5 \mu \mathrm{M}$ staurosporine for $18 \mathrm{~h}$ as a positive control. D. Effect on cell cycle distribution. Cells were treated with $10 \mu \mathrm{M}$ sorafenib and/or $5 \mu \mathrm{M}$ cisplatin. Cell cycle distributions were determined by flow cytometry for up to $72 \mathrm{~h}$ post treatment. 


\section{Effect of sorafenib on combined treatment}

To test whether sorafenib influences the interaction of irradiation and cisplatin, we analyzed the cellular radiosensitivity in the presence of either cisplatin or cisplatin and sorafenib $(10 \mu \mathrm{M})$ under delayed plating conditions. Because of the strong cytotoxic effect of cisplatin we used only $1 \mu \mathrm{M}$ cisplatin for these experiments.

Cisplatin caused a radiosensitization in three of the cells lines (FaDu, SAS, UT-SCC 60B) (Figure 4A). This sensitization was abrogated by sorafenib in $\mathrm{FaDu}$ cells but was not affected in SAS and UT-SCC 60B cells. Furthermore, sorafenib caused a slight but significant sensitization in cisplatin-treated UT-SCC 42A cells at low doses. The effect of cisplatin and sorafenib without IR is depicted in the inlays.

To summarize, sorafenib caused heterogeneous effects when combined with IR and cisplatin. However, when the effects of cisplatin and sorafenib were not normalized to the intrinsic cytotoxicity (non transformed values) it becomes obvious that the triple combination of IR, cisplatin and sorafenib causes a massive cell inactivation. This cell inactivation was always stronger compared to the treatment of HNSCC cells with IR, IR + cisplatin or IR + sorafenib, alone (Figure 4B).

\section{Effect of sorafenib on normal fibroblasts}

One limiting parameter for combining tyrosine kinase inhibitors like sorafenib with CRT could be the side effects induced by massive inactivation of normal cells. Therefore, we asked, if addition of sorafenib to cisplatin and irradiation enhances cell inactivation of normal cells in the colony formation assay by treating NF under delayed plating conditions. Although sorafenib alone
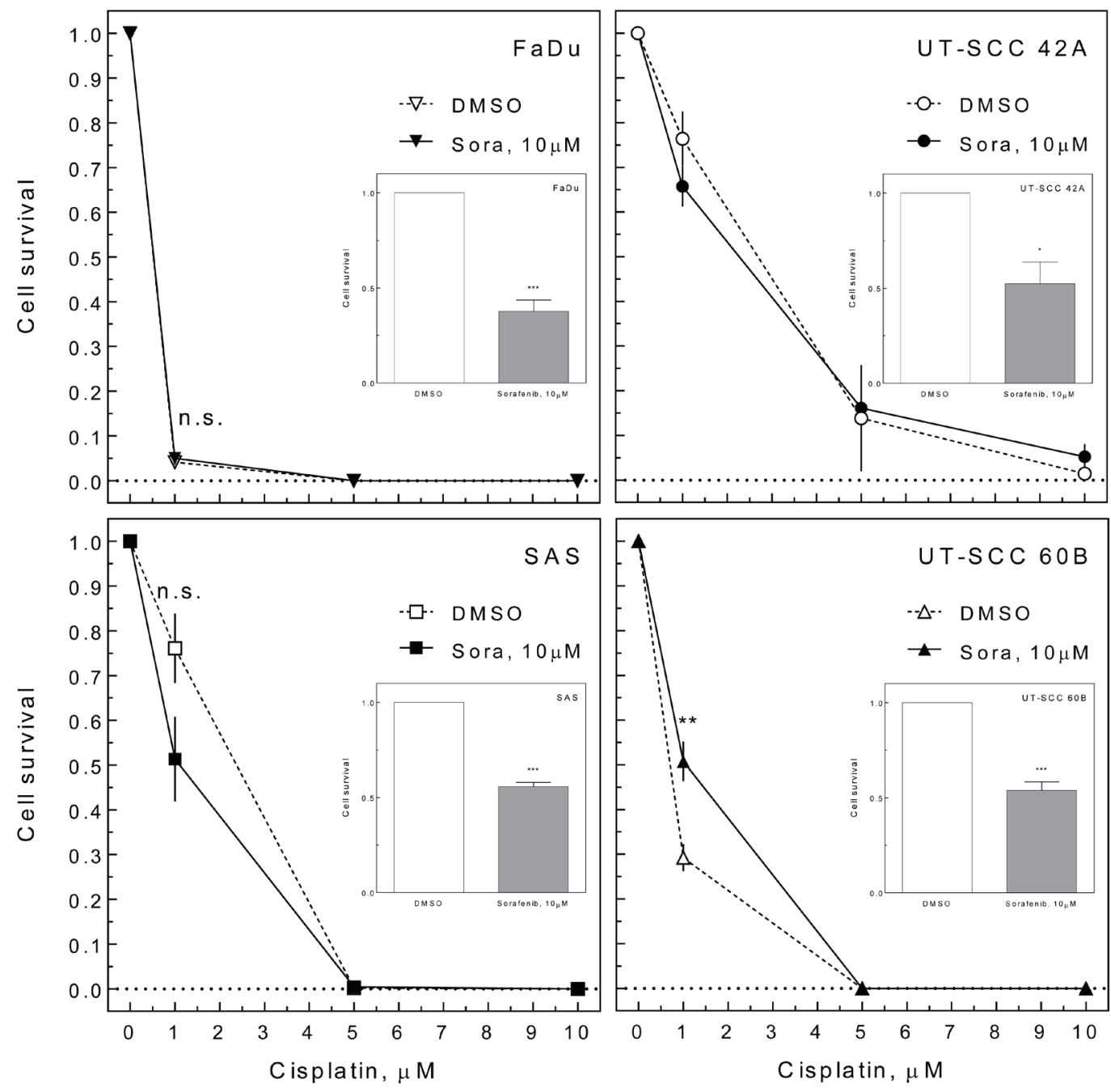

Figure 3: Effect of sorafenib on cisplatin-induced cell inactivation. HNSCC cells were treated with $10 \mu \mathrm{M}$ sorafenib and increasing concentrations of cisplatin for $24 \mathrm{~h}$. The medium was changed and cell inactivation was measured by colony forming assay (preplating). The relative cell survival is depicted including the effect of sorafenib treatment alone (inlays). 
A
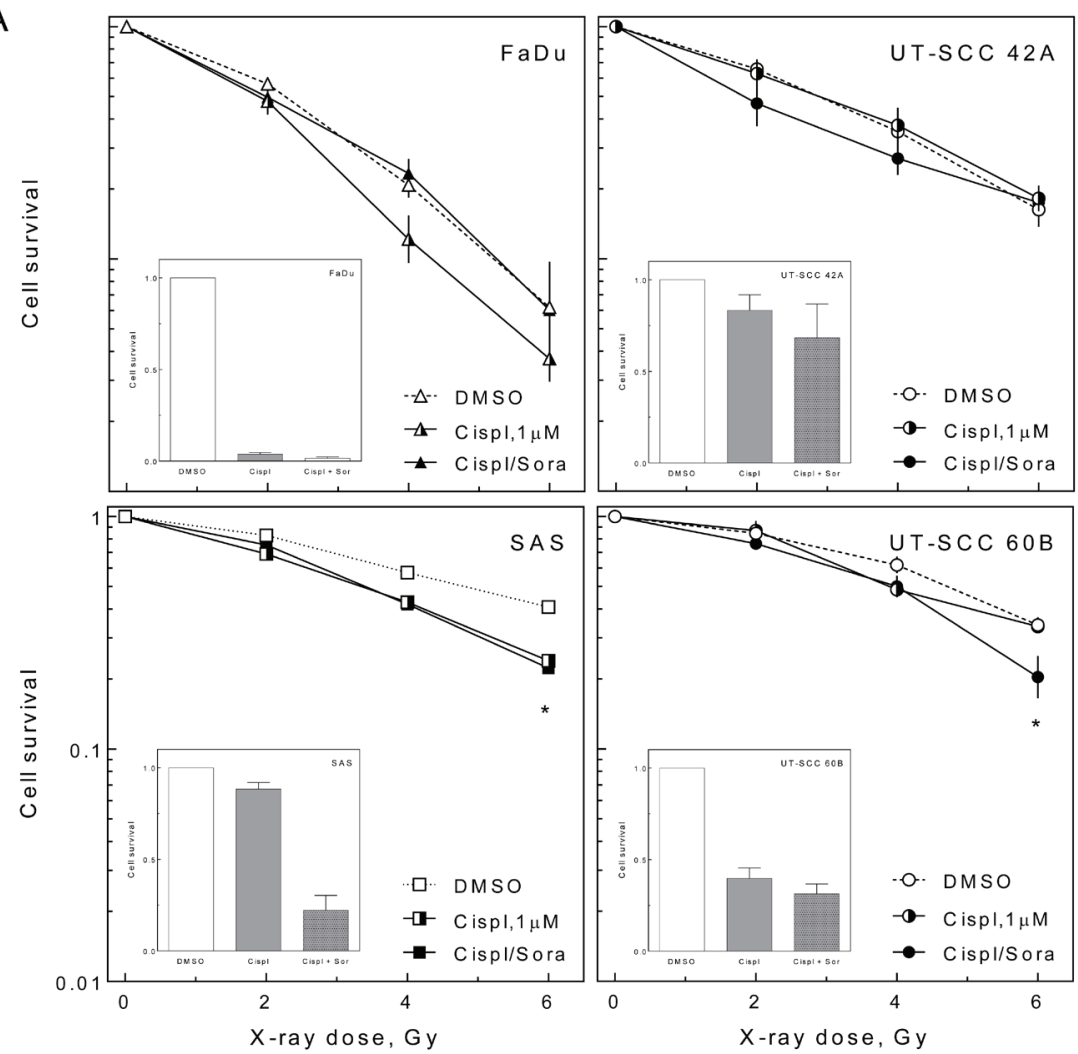

B
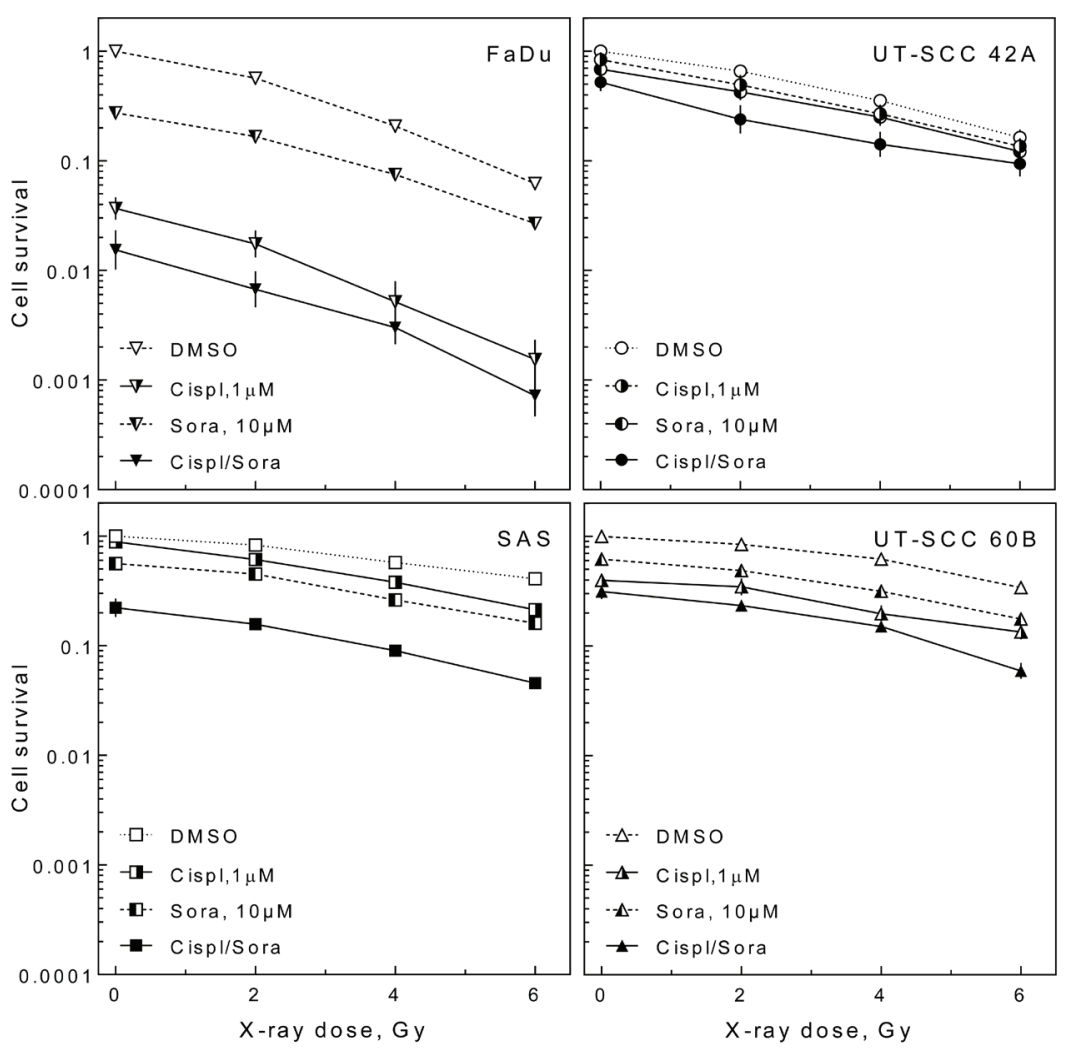

Figure 4: Effect of sorafenib on cell inactivation after combined treatment. HNSCC cells were treated with $10 \mu \mathrm{M}$ sorafenib and $1 \mu \mathrm{M}$ cisplatin for $2 \mathrm{~h}$ before cells were irradiated using different doses. Twenty-four hours later cells were re-plated and cell inactivation was measured by colony forming assay (delayed plating). A. Relative cell survival (transformed values) including the effect of cisplatin and cisplatin + sorafenib treatment alone (inlays). B. Non transformed values. 
caused cell inactivation in NF, the cell inactivation induced by cisplatin was significantly reduced when sorafenib was added (Figure 5A). Furthermore, no radiosensitization was observed by sorafenib in NF contrary to HNSCC cells (Figure 5B, left panel). In contrast, cisplatin induced a modest, yet significant radiosensitization (Figure 5B, central panel). Strikingly this was reverted by the addition of sorafenib (Figure 5B, right panel). All together the sorafenib treatment resulted in an improved cell survival of irradiated and cisplatin-treated NF as shown by Figure $5 \mathrm{C}$, displaying non transformed values.

\section{DISCUSSION}

In this study we investigated the effect of sorafenib on HNSCC and normal cells treated with both irradiation and cisplatin in order to evaluate this combination for further pre-clinical and potential clinical investigations.

We could demonstrate that sorafenib enhances radiosensitivity, which is in line with our previous data [14]. This radiosensitization can be observed in approximately a quarter of the HPV-negative HNSCC cell lines tested (data not shown), indicating that this is a frequent phenomenon. Furthermore, this sensitization was observed under experimental conditions (delayed plating) in which, for example, EGFR inhibitors failed to sensitize various tumor cell lines $[8,19]$. As delayed plating results are thought to better reflect tumor cell killing in vivo, the observed radiosensitization is expected to translate into improved tumor control [8].

In combination with cisplatin we observed heterogeneous responses ranging from sensitization (SAS) to resistance (UT-SCC 60B). Nevertheless, these effects were quite small and when sorafenib was added to chemoradiation treatment, all cell lines displayed improved overall cell inactivation, regardless of any radioor chemosensitization (Figure 4B). Therefore, sorafenib is a promising candidate for combined targeted treatment of HNSCC which warrants further investigation.

In clinical practice, cisplatin is added to ionizing radiation because of its clinically observed radiosensitizing effect, reflected by higher survival and response rates of

\section{A}

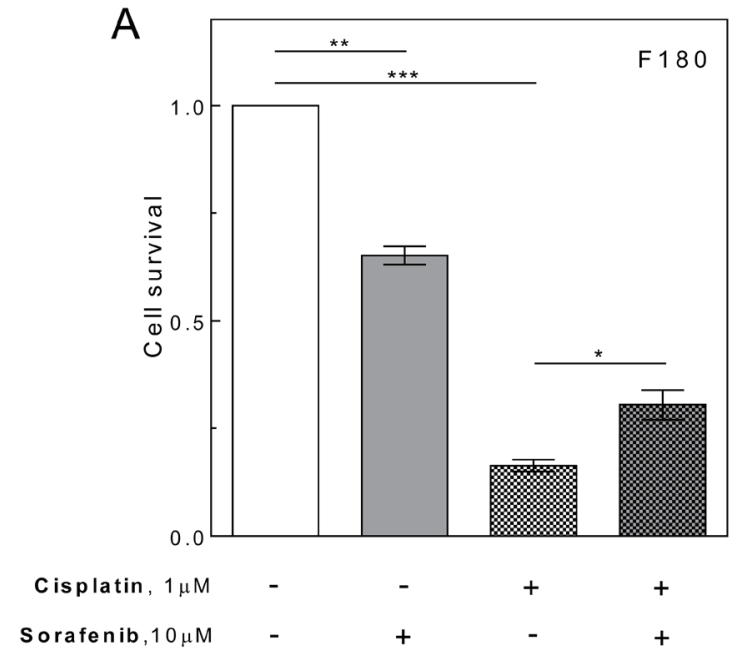

C

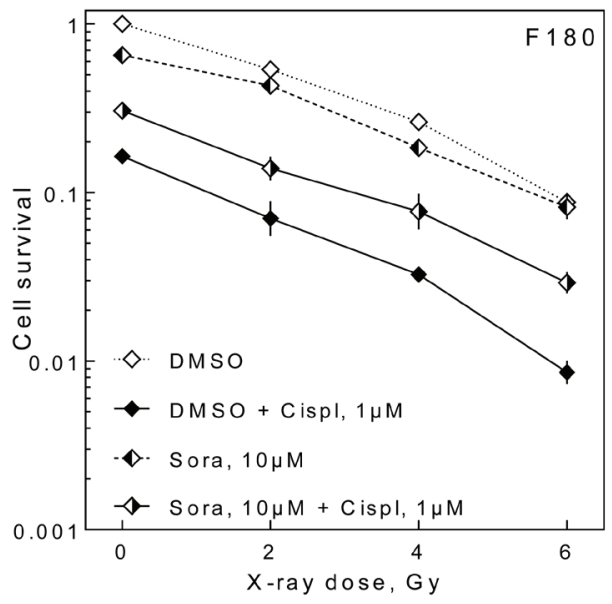

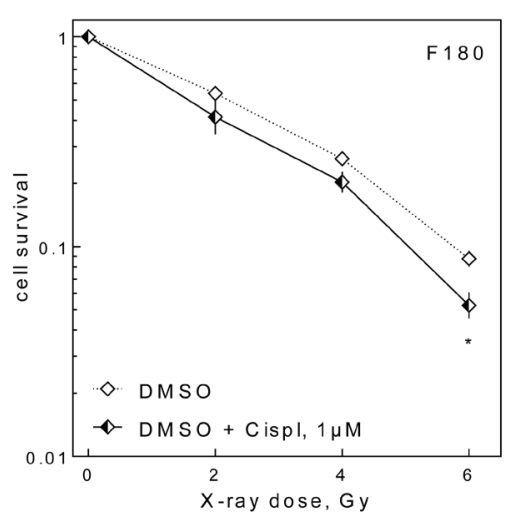
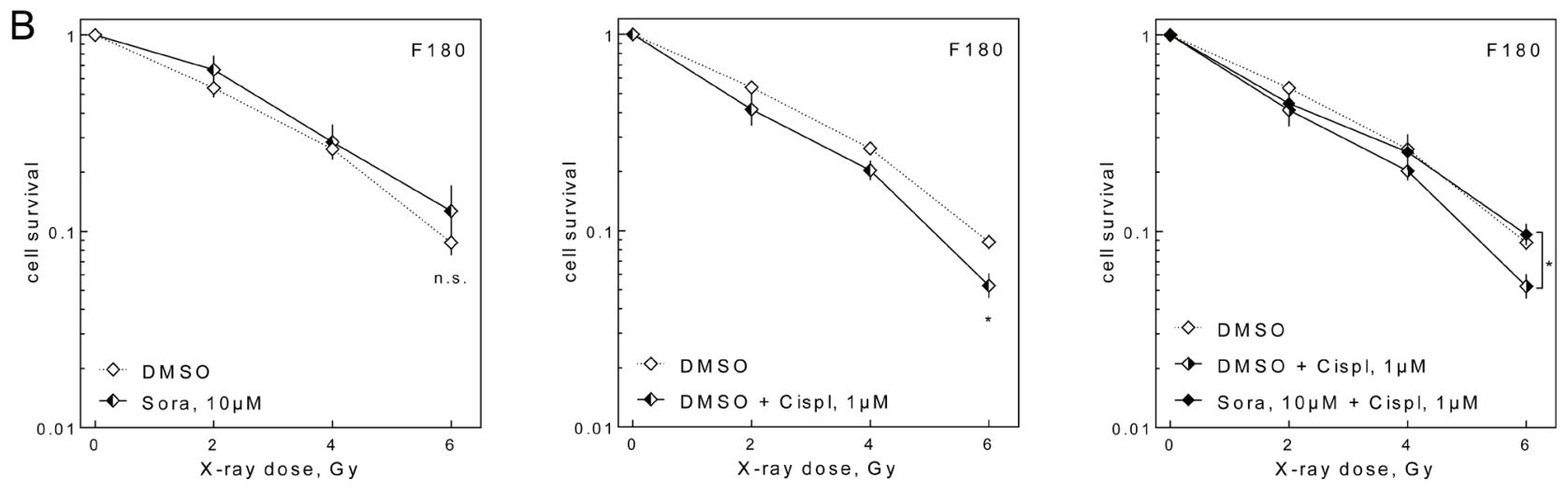

Figure 5: Effect of sorafenib on NF. Relative cell survival as measured by colony forming assay using F180 NF treated with $10 \mu \mathrm{M}$ sorafenib and $1 \mu \mathrm{M}$ cisplatin as indicated. A. Unirradiated cells. B. Relative effect of sorafenib (left), cisplatin (center) and combined (right) treatment on radiosensitivity (transformed values). C. Non-transformed values. 
HNSCC patients treated with CRT versus RT alone [2, 3]. In this study we observed cellular radiosensitization by cisplatin in three out of four HNSCC cell lines. This sensitization was diminished by sorafenib in FaDu cells. However, as mentioned above, reduced overall cell survival could be observed in all triple-treated samples compared to the cisplatin and IR-treated samples. This argues for an addition of sorafenib to CRT even for cells / tumors which are not chemo- or radiosensitized by sorafenib. This is of relevance since some clinical trials combining targeted therapeutics and CRT could show even a lower antitumor activity, albeit not statistically significant, for patients receiving the targeted agent in addition to CRT [5, 20, 21].

To improve treatment outcome for HNSCC patients distinct tyrosine kinase inhibitors (TKI) in combination with cisplatin-based CRT are under extensive clinical investigation (NCT01737008, NCT01427478, NCT01824823, NCT02131155, NCT00442455, NCT00629226). However, different TKI tested in combination with cisplatin and RT, namely erlotinib, gefitinib and lapatinib, failed to show an improvement in survival but caused increased toxicity in most trials [2227]. Our data now suggest that sorafenib might improve tumor control by improving tumor cell inactivation. However, until now, no clinical data exist on the effects of sorafenib in the combined treatment with cisplatin-based CRT in HNSCC. One planned clinical trial investigating the triple combination has been withdrawn before enrollment (NCT00627835). There is data from single arm trials on the efficacy of sorafenib monotherapy and the combined treatment with alkylating agents, such as carboplatin and cisplatin, in recurrent/metastatic HNSCC (RM-HNSCC) [12, 13, 28-30]. In summary, sorafenib combined with cisplatin seems to have an encouraging efficacy profile with tolerable toxicity in most studies. However, a severe risk for side effects such as hand-foot syndrome (HFS) and myelosuppression was observed in the above trials. Therefore, these adverse effects must be taken into consideration in the application of sorafenib. On a cellular level we could show here that sorafenib protected normal cells from inactivation by cisplatin. Whether this translates to normal tissue protection in an in vivo setting remains to be seen.

All together these data provide evidence that sorafenib is a promising targeted agent that could potentially be added to cisplatin-based CRT, as it may make treatment both more effective and less toxic.

\section{MATERIALS AND METHODS}

\section{Substances}

Sorafenib (tyrosine-kinase inhibitor, Nexavar ${ }^{\circledR}$, Bayer HealthCare, Leverkusen, Germany), cisplatin (alkylating agent, Medac, Wedel, Germany), staurosporine (Calbiochem/Merck, Darmstadt, Germany), colcemid (Merck, Darmstadt, Germany), DMSO (vehicle; Roche), propidium iodide (Merck, Darmstadt, Germany), RNase A (Serva, Heidelberg, Germany).

\section{Cell culture}

HPV-negative HNSCC cell lines UT-SCC 42A and UT-SCC 60B were obtained from Reidar Grénman (University of Turku, Finland). HNSCC cells and normal human fibroblasts (NF) F180 were grown in Dulbecco's Modified Eagle's Medium (Life technologies, Carlsbad, CA, USA) containing 10\% fetal bovine serum (Biochrome AG, Berlin, Germany) and $4 \mathrm{mM}$ glutamine (Life technologies, Carlsbad, CA, USA) at $37^{\circ} \mathrm{C}, 10 \%$ $\mathrm{CO}_{2}$ and $100 \%$ humidification. HNSCC cell lines were authenticated by short tandem repeat analysis (Department of Human Genetics, UKE, Hamburg, Germany).

\section{Irradiation (IR)}

Cells were irradiated at room temperature with a single dose with $200 \mathrm{kV}$ X-rays (Gulmay RS225, Gulmay Medical Ltd., Byfleet, UK; $15 \mathrm{~mA}, 0.8 \mathrm{~mm} \mathrm{Be}+0.5 \mathrm{~mm}$ $\mathrm{Cu}$ filtering; dose rate of $1.2 \mathrm{~Gy} / \mathrm{min}$ ).

\section{Proliferation}

For proliferation assays, $1 \times 10^{5}$ cells were seeded into T24 culture flasks. Twenty-four hours later they were treated with different concentrations of sorafenib, dissolved in DMSO or a combined treatment of sorafenib $(5 \mu \mathrm{M})$ and different concentrations of cisplatin. Cell numbers were determined at the indicated time points.

\section{Cell survival}

Cell survival was measured by colony formation. To analyze the cisplatin-sensitivity 500-1000 cells were seeded into T25 culture flasks and were treated with cisplatin, sorafenib or a combination of both $24 \mathrm{~h}$ later and the medium was exchanged $24 \mathrm{~h}$ later (pre-plating). To analyze radiosensitivity, exponentially growing cells were treated with cisplatin, sorafenib or a combination two hours before irradiation. Cells were harvested and re-plated 
(500-1000 cells) $24 \mathrm{~h}$ after irradiation (delayed plating). NF were re-plated using AmnioMax C-100 Basal Medium (Life technologies, Carlsbad, CA, USA) containing 10\% FCS and C-100 supplement (Life technologies, Carlsbad, CA, USA) to optimize colony formation. Cells were allowed to grow until colonies reached equal size, fixed with $70 \%$ ethanol and stained with crystal violet. Colonies of more than 50 cells were counted by an observer who was blinded to treatment. Unless indicated otherwise, absolute numbers were normalized to the unirradiated controls (transformed values).

\section{Apoptosis}

For the detection of apoptosis, caspase activity (caspase-1, -3, -4, -5, -6, -7, -8 and -9), was analyzed by flow cytometry $72 \mathrm{~h}$ after cisplatin and sorafenib treatment using the Carboxyfluorescin FLICA Apoptosis Detection Kit Caspase Assay (Immunochemistry Technologies, LLC, Bloomington, MN, USA), according to the manufacturer's protocol. Staurosporin served as a positive control. Sorafenib and cisplatin were removed $24 \mathrm{~h}$ after treatment by medium exchange.

\section{Cell cycle}

Exponentially growing cells were treated with cisplatin, sorafenib or a combination of both. Sorafenib and cisplatin were removed $24 \mathrm{~h}$ after treatment by medium exchange and cells were harvested $0 \mathrm{~h}, 24 \mathrm{~h}$ and $48 \mathrm{~h}$ thereafter. Cells were fixed by $70 \%$ ethanol, washed with PBS (0.1\% Tween) and the DNA was stained with propidium iodide (PI, $10 \mu \mathrm{g} / \mathrm{ml})$ containing RNase A (RNase A $0.1 \mu \mathrm{g} / \mathrm{ml}$ ) for $30 \mathrm{~min}$ at room temperature. DNA histograms were constructed using flow cytometry (FACS Scan Canto and FACSDiva software, BD Biosciences, Franklin Lakes, NJ, USA) and the fraction of G1, S and G2 phase cells was calculated using ModFit LT $^{\mathrm{TM}}$ software (Verity Software House, Inc., Topsham, ME, USA).

\section{Data evaluation}

Unless indicated otherwise, experiments were repeated at least three times $(n=3)$. The data are presented as mean values $( \pm$ SEM). GraphPad Prism 6 (GraphPad Software, Inc., La Jolla, CA, USA) was used for analyzing and graphing the data. Student's $t$-test was performed for the statistical analysis. $p$-values were calculated using unpaired two sided tests $(* p<0.05$; ** $p<0.01$; *** $p$ $<0.001)$

\section{ACKNOWLEDGMENTS}

The authors thank Bayer HealthCare for providing sorafenib.

\section{CONFLICTS OF INTEREST}

M. Kriegs has received sorafenib from Bayer HealthCare. R. Knecht is an advisory board member of Merck Serono, Sanofi Aventis, Boehringer Ingelheim and Bayer HealthCare. All other authors declare no conflict of interest.

\section{GRANT SUPPORT}

This work was supported in part by a 2014 research grant from the University Cancer Center Hamburg (N.M.), the University Medical Center Hamburg-Eppendorf (FFM, M.K.) as well as by the City of Hamburg, Landesexzellenzinitiative Hamburg (LEXI 2012; Tumor targeting via cell surface molecules essential in cancer progression and dissemination, M.K., E.D.), the Federal Ministry of Education and Research (BMBF 02NUK032, M.K, E.D.), the Erich \& Gertrud Roggenbuck-Stiftung (M.K.) and the Spierling Stiftung (M.K.).

\section{Editorial note}

This paper has been accepted based in part on peerreview conducted by another journal and the authors' response and revisions as well as expedited peer-review in Oncotarget.

\section{REFERENCES}

1. Bernier J. A multidisciplinary approach to squamous cell carcinomas of the head and neck: an update. Current opinion in oncology. 2008; 20:249-255.

2. Pignon JP, le Maitre A, Maillard E and Bourhis J. Metaanalysis of chemotherapy in head and neck cancer (MACHNC): an update on 93 randomised trials and 17,346 patients. Radiother Oncol. 2009; 92:4-14.

3. Blanchard P, Baujat B, Holostenco V, Bourredjem A, Baey C, Bourhis J and Pignon JP. Meta-analysis of chemotherapy in head and neck cancer (MACH-NC): a comprehensive analysis by tumour site. Radiother Oncol. 2011; 100:33-40.

4. Budach W, Hehr T, Budach V, Belka C and Dietz K. A meta-analysis of hyperfractionated and accelerated radiotherapy and combined chemotherapy and radiotherapy regimens in unresected locally advanced squamous cell carcinoma of the head and neck. BMC Cancer. 2006; 6:28. 
5. Ang KK. A randomized phase III trial (RTOG 0522) of concurrent accelerated radiation plus cisplatin with or without cetuximab for stage III-IV head and neck squamous cell carcinomas. J Clin Oncol. 2014; 32:2940-50.

6. Forastiere AA, Zhang Q, Weber RS, Maor MH, Goepfert H, Pajak TF, Morrison W, Glisson B, Trotti A, Ridge JA, Thorstad W, Wagner H, Ensley JF and Cooper JS. Long-term results of RTOG 91-11: a comparison of three nonsurgical treatment strategies to preserve the larynx in patients with locally advanced larynx cancer. Journal of clinical oncology. 2013; 31:845-852.

7. Mockelmann N, Kriegs M, Lorincz BB, Busch CJ and Knecht R. Molecular targeting in combination with platinum-based chemoradiation in head and neck cancer treatment. Head Neck. 2016; 38 Suppl 1:E2173-81. doi: 10.1002/hed.24031.

8. Kriegs M, Gurtner K, Can Y, Brammer I, Rieckmann T, Oertel R, Wysocki M, Dorniok F, Gal A, Grob TJ, Laban S, Kasten-Pisula U, Petersen C, Baumann M, Krause M and Dikomey E. Radiosensitization of NSCLC cells by EGFR inhibition is the result of an enhanced p53-dependent G1 arrest. Radiother Oncol. 2015; 115:120-127.

9. Benson AB, 3rd, Abrams TA, Ben-Josef E, Bloomston PM, Botha JF, Clary BM, Covey A, Curley SA, D'Angelica MI, Davila R, Ensminger WD, Gibbs JF, Laheru D, Malafa MP, Marrero J, Meranze SG, et al. NCCN clinical practice guidelines in oncology: hepatobiliary cancers. J Natl Compr Canc Netw. 2009; 7:350-391.

10. Motzer RJ, Agarwal N, Beard C, Bolger GB, Boston B, Carducci MA, Choueiri TK, Figlin RA, Fishman M, Hancock SL, Hudes GR, Jonasch E, Kessinger A, Kuzel TM, Lange PH, Levine EG, et al. NCCN clinical practice guidelines in oncology: kidney cancer. J Natl Compr Canc Netw. 2009; 7:618-630.

11. Tuttle RM, Haddad RI, Ball DW, Byrd D, Dickson P, Duh QY, Ehya H, Haymart M, Hoh C, Hunt JP, Iagaru A, Kandeel F, Kopp P, Lamonica DM, Lydiatt WM, McCaffrey J, et al. Thyroid carcinoma, version 2.2014. Journal of the National Comprehensive Cancer Network. 2014; 12:1671-1680; quiz 1680.

12. Elser C, Siu LL, Winquist E, Agulnik M, Pond GR, Chin SF, Francis P, Cheiken R, Elting J, McNabola A, Wilkie $\mathrm{D}$, Petrenciuc $\mathrm{O}$ and Chen EX. Phase II trial of sorafenib in patients with recurrent or metastatic squamous cell carcinoma of the head and neck or nasopharyngeal carcinoma. J Clin Oncol. 2007; 25:3766-3773.

13. Williamson SK, Moon J, Huang $\mathrm{CH}$, Guaglianone PP, LeBlanc M, Wolf GT and Urba SG. Phase II evaluation of sorafenib in advanced and metastatic squamous cell carcinoma of the head and neck: Southwest Oncology Group Study S0420. J Clin Oncol. 2010; 28:3330-3335.

14. Laban S, Steinmeister L, Gleissner L, Grob TJ, Grenman R, Petersen C, Gal A, Knecht R, Dikomey E and Kriegs M. Sorafenib sensitizes head and neck squamous cell carcinoma cells to ionizing radiation. Radiother Oncol.
2013; 109:286-92.

15. Heravi M, Tomic N, Liang L, Devic S, Holmes J, Deblois F, Radzioch D and Muanza T. Sorafenib in combination with ionizing radiation has a greater anti-tumour activity in a breast cancer model. Anticancer Drugs. 2012; 23:525-533.

16. Plastaras JP, Kim SH, Liu YY, Dicker DT, Dorsey JF, McDonough J, Cerniglia G, Rajendran RR, Gupta A, Rustgi AK, Diehl JA, Smith CD, Flaherty KT and El-Deiry WS. Cell cycle dependent and schedule-dependent antitumor effects of sorafenib combined with radiation. Cancer research. 2007; 67:9443-9454.

17. Suen AW, Galoforo S, Marples B, McGonagle M, Downing L, Martinez AA, Robertson JM and Wilson GD. Sorafenib and radiation: a promising combination in colorectal cancer. International journal of radiation oncology, biology, physics. 2010; 78:213-220.

18. Yadav A, Kumar B, Teknos TN and Kumar P. Sorafenib enhances the antitumor effects of chemoradiation treatment by downregulating ERCC-1 and XRCC-1 DNA repair proteins. Mol Cancer Ther. 2011; 10:1241-1251.

19. Struve N, Riedel M, Schulte A, Rieckmann T, Grob TJ, Gal A, Rothkamm K, Lamszus K, Petersen C, Dikomey E and Kriegs M. EGFRvIII does not affect radiosensitivity with or without gefitinib treatment in glioblastoma cells. Oncotarget. 2015; 6:33867-77. doi: 10.18632/ oncotarget.5293.

20. Crosby T, Hurt CN, Falk S, Gollins S, Mukherjee S, Staffurth J, Ray R, Bashir N, Bridgewater JA, Geh JI, Cunningham D, Blazeby J, Roy R, Maughan T and Griffiths G. Chemoradiotherapy with or without cetuximab in patients with oesophageal cancer (SCOPE1): a multicentre, phase 2/3 randomised trial. Lancet Oncol. 2013; 14:627637.

21. Giralt J, Fortin A, Mesia R, Minn H, Henke M, Yunes Ancona A, Cmelak A, Markowitz AB, Hotte SJ, Singh S, Chan ATC, Merlano MC, Zhang A, Oliner KS and Vanderwalde AM. A phase II, randomized trial (CONCERT-1) of chemoradiotherapy (CRT) with or without panitumumab (pmab) in patients (pts) with unresected, locally advanced squamous cell carcinoma of the head and neck (LASCCHN). ASCO Meeting Abstracts. 2012; 30:5502.

22. Martins RG, Parvathaneni U, Bauman JE, Sharma AK, Raez LE, Papagikos MA, Yunus F, Kurland BF, Eaton KD, Liao JJ, Mendez E, Futran N, Wang DX, Chai X, Wallace SG, Austin M, et al. Cisplatin and Radiotherapy With or Without Erlotinib in Locally Advanced Squamous Cell Carcinoma of the Head and Neck: A Randomized Phase II Trial. J Clin Oncol. 2013; 31:1415-21. doi: 10.1200/ JCO.2012.46.3299.

23. Hayes DN, Raez LE, Sharma AK, Papagikos MA, Yunus F, Parvathaneni U, Eaton KD, Futran N, Wallace SG and Martins R. Multicenter randomized phase II trial of combined radiotherapy and cisplatin with or without erlotinib in patients with locally advanced squamous cell 
carcinoma of the head and neck (SCCAHN): Preliminary toxicity results. ASCO Meeting Abstracts. 2010; 28:5580.

24. Gregoire V, Hamoir M, Chen C, Kane M, Kawecki A, Julka PK, Wang HM, Prasad S, D’Cruz AK, RadosevicJelic L, Kumar RR, Korzeniowski S, Fijuth J, Machiels JP, Sellers MV, Tchakov I, et al. Gefitinib plus cisplatin and radiotherapy in previously untreated head and neck squamous cell carcinoma: a phase II, randomized, doubleblind, placebo-controlled study. Radiother Oncol. 2011; 100:62-69.

25. Singh C. Gefitinib with concurrent chemoradiation in locally advanced head and neck cancers. ASCO Meeting Abstracts. 2014; 32:6054.

26. Harrington K, Berrier A, Robinson M, Remenar E, Housset M, de Mendoza FH, Fayette J, Mehanna H, El-Hariry I, Compton N, Franklin N, Biswas-Baldwin N, Lau M, Legenne P and Kumar R. Randomised Phase II study of oral lapatinib combined with chemoradiotherapy in patients with advanced squamous cell carcinoma of the head and neck: rationale for future randomised trials in human papilloma virus-negative disease. European journal of cancer. 2013; 49:1609-1618.

27. Harrington KJ, Temam S, D'Cruz A, Jain MM, D'Onofrio I, Manikhas GM, Horvai G, Sun Y, Dietzsch S, Dubinsky P, Holeckova P, Mehanna H, El-Hariry I, Franklin N, BiswasBaldwin N, Legenne P, et al. Final analysis: A randomized, blinded, placebo (P)-controlled phase III study of adjuvant postoperative lapatinib (L) with concurrent chemotherapy and radiation therapy (CH-RT) in high-risk patients with squamous cell carcinoma of the head and neck (SCCHN). ASCO Meeting Abstracts. 2014; 32:6005.
28. Blumenschein GR, Glisson BS, Lu C, Sabichi AL, Ginsberg LE, Bartos CI, Feng L, Tran HT, El-Naggar AK, Lippman SM and Kies MS. Final results of a phase II study of sorafenib in combination with carboplatin and paclitaxel in patients with metastatic or recurrent squamous cell cancer of the head and neck (SCCHN). ASCO Meeting Abstracts. 2012; 30:5592.

29. Savvides PPK, Maura L. Gillison, Ted Teknos. A phase I/II clinical trial of sorafenib in combination with cisplatin and docetaxel in patients with recurrent/metastatic squamous cell carcinoma of the head and neck (SCCHN). J Clin Oncol 32:5s, 2014 (suppl; abstr TPS6103). 2014 ASCO Annual Meeting.

30. Xue C, Yu Q, Pan J-j, Sun Y and Zhang L. A phase II study of sorafenib in combination with cisplatin and 5-fluorouracil in the treatment of recurrent or metastatic nasopharyngeal carcinoma. ASCO Meeting Abstracts. 2012; 30:5538. 